\title{
INVESTIGATION OF A NEW DESIGN OF INVERSE DIFFUSION FLAME BURNER
}

\author{
M. M. Abdelaal, S. M. Ali, A. M. Radwan and A. A. Ismail \\ Al Azhar University in Cairo, Faculty of Engineering
}

\begin{abstract}
ملخص البحث
اللهب الانتشاري ينت استخدامه على نطاق و اسع بدلا من سابق الخلط وذللك لكونه اكثر ثباتا ولكنه اقل كفاءه وينتج

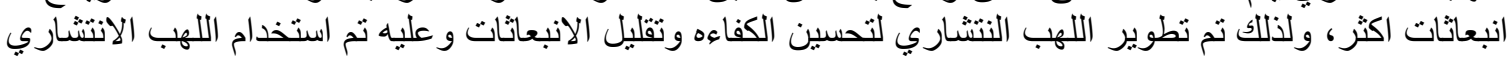

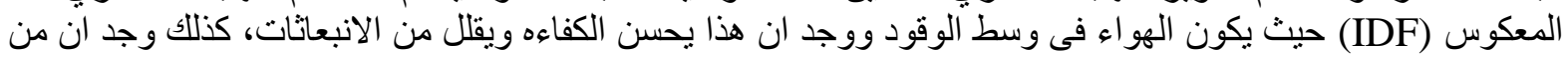

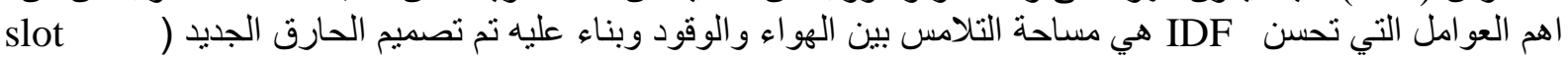

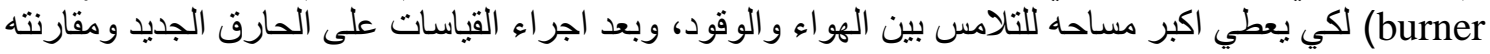
بالحارق المعتاد وجد ان درجة حر ارته اعلى بحو الي Co \% $\& \mathrm{Co}_{2} \%$
\end{abstract}

\begin{abstract}
Diffusion flame are used in a wide range instead of premixed flame because it is more safe, although it produces more emissions and is less efficient than the premixed flame. Some applications require unconfined diffusion flames which are known to be worse than confined ones, from the point of view of efficiency and the relatively large amount of combustion air requirements. Therefore, the development of unconfined diffusion flames to improve its efficiency, emissions and air power consumption becomes know necessarily required. The inverse diffusion flame introduces a small amount of air (high equivalence ratios) in the center of flame and the fuel is at the circumference. The fuel is diffused inward to in and form good mixing with the central air, meanwhile the outer atmospheric air can diffuse in the fuel to help substitute the deficiency of central air and hence improve the combustion efficiency. It has been found that one of the main factors affecting the inverse diffusion flame performance is the contact area between fuel and air. The present design of a novel inverse diffusion flame burner increases the contact area to maximum between the central air and the outer fuel. The new design uses consecutive slots (rectangular shaped) i.e. fuel-air-fuel instead of coaxial circular burner. Many measurements were carried out on the new burner (slot) and the conventional one (coaxial) including mainly, the axial temperature, the flame appearance, and the axial gas analysis. The comparison between the new and the conventional burners reveals that the axial flame temperature is about $400{ }^{\circ} \mathrm{C}$ higher than that of coaxial one, also the entrainments area is increased, and the combustion efficiency is improved which is indicated the increase of $\mathrm{CO}_{2}$ and the reduction of $\mathrm{O}_{2}$ percentages in the axial gas analysis.
\end{abstract}

\section{Keywords: Inverse Diffusion, Flames, Unconfined Flame.}

\section{INTRODUCTION}

Flames are mainly two types: premixed flame and Diffusion flame. Premixed flame has advantages like high heat release, high flame temperature and soot free flame structure $[1,2]$. However, it has some disadvantage such as flashback, easy to blow off and low stability. To 
improve these characteristics, it is require to have additional system, which is used to be a pilot flame, but pilot flame makes burner design more complicated and more expensive [3, 4]. Diffusion flame provides safe combustion and low tendency to blow off, but it has long yellow flame which is indicating low heat release, excess soot emission and too long flame length due to incomplete combustion $[5,6]$.

Inverse Diffusion flame IDF is a special type of Diffusion flame, In Diffusion flame the fuel is at the center of the burner, but for IDF the air is at the center of the burner and the fuel is at the circumference of the air, which makes a high momentum of air induced strong entrainment of the surrounding fuel giving a good mixing between air and fuel, so that IDF gives a considerable reduced soot emission and flame length less than diffusion flame, So that IDF has both advantages of premixed flame and diffusion flame $[7,8,9,10]$.

The study of IDF is divided into six types according to flame appearance and stability, it has been found that IDF and diffusion flame have the same visual appearance in confined space [11].

A computational model for $\mathrm{H}_{2}$ found that flame tip temperature for IDF is higher than Diffusion flame and the range of temperatures for IDF is higher than Diffusion flame [12].

The study of IDF found that it has less soot formation than Diffusion flame [13]. And the peak soot volume fraction for IDF is less than Diffusion flame [14].

A comparative study between IDF and a new design called CAP (circumferential arrangement port) has been carried out [10]. In CAP burner the air jet is at the center of the burner and the fuel is divided into several fuel jets at the circumference of the air. They found that, the entrainment of high momentum air jet and low momentum fuel jet and the increasing of contact area between air and fuel give a good mixing characteristics than IDF which make CAP IDF is better than IDF [10].

The present study is a trial to maximize the contact area between the air and fuel, therefore, it uses a slot burner instead of circular shape burner, and also the intermediate separation distance between the air and fuel can be varied without the variation of the contact area.

\section{EXPERIMENTAL SET-UP}

Fig. 1 illustrates a plan view for the two burner used in the present study (Co-Axial and Slot). CoA burner consists of two concentric tubes the air is at the center with inner diameter of $22.5 \mathrm{~mm}$ and thickness of 3 $\mathrm{mm}$, and fuel is at the outer tube with inner diameter $42.5 \mathrm{~mm}$.

Slot burner consists of three exit stream with slot cross sectional area (slot is a rectangle where length is much larger than width). The three slots have the same dimension $66.26 \mathrm{~mm}$ length and $6 \mathrm{~mm}$ width the wall thickness between each slot is $3 \mathrm{~mm}$. The areas of two burners under investigation are taken to be the same also the flow rates (fuel and air) are the same which results the same velocities of the flow of air and fuel for the two burners.

Fig. 2 illustrates schematic diagram for test setup. The fuel used in the tests is commercial LPG (liquefied petroleum gas) which has a composition of $70 \%$ butane and $30 \%$ propane.

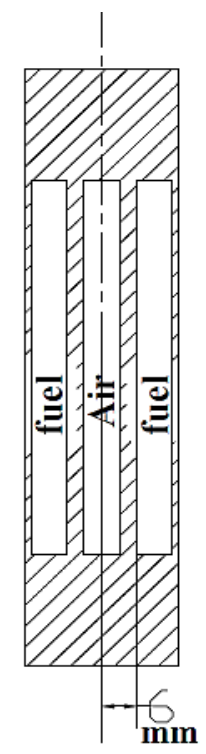

slot

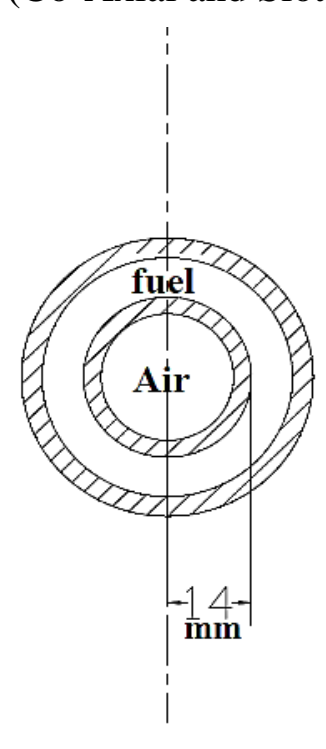

Coaxial

Fig. 1 Plan view of Coaxial and slot burners

The air is used as the oxidizer.

A calibrated electromagnetic rotameter (KDG) was used to measure the air flow rate. The rotameter has an accuracy of $\pm 2 \%$ of full scale and has a turndown ratio of 1 to 10 . A calibrated thermal mass flow meters (FMA 1700/1800) was used to measure the gas flow rate with accuracy $\pm 1.5 \%$ of full scale. 
Burner is fixed on its position on the test chasse while the measuring probe (thermocouple or gas sampling probe) is fixed on a holder of a transverse mechanism which has three directional movement facility $(\mathrm{X}, \mathrm{Y}$, and $\mathrm{Z})$.

Flame appearance and length are measured by visual observation and getting photos by professional camera CANON EOS 650D. The temperature measured with a bare thermocouple type $\mathrm{B}$ with $\mathrm{Pt}-30 \% / \mathrm{Rh}$ versus $\mathrm{Pt}-6 \% / \mathrm{Rh}$. The lead wire diameter is equal to $0.3 \mathrm{~mm}$ and the bead diameter is $1 \mathrm{~mm}$. The thermocouple was clamped at the holder of a positioning system and moved through the burner center line by interval of $5 \mathrm{~mm}$. The measured temperature data was collected on the data acquisition system as a function of time and the mean value of each point is obtained. The measuring temperatures are corrected for radiation losses according to references $[15,16]$. The maximum temperature error was 150 ${ }^{\circ} \mathrm{C}$.

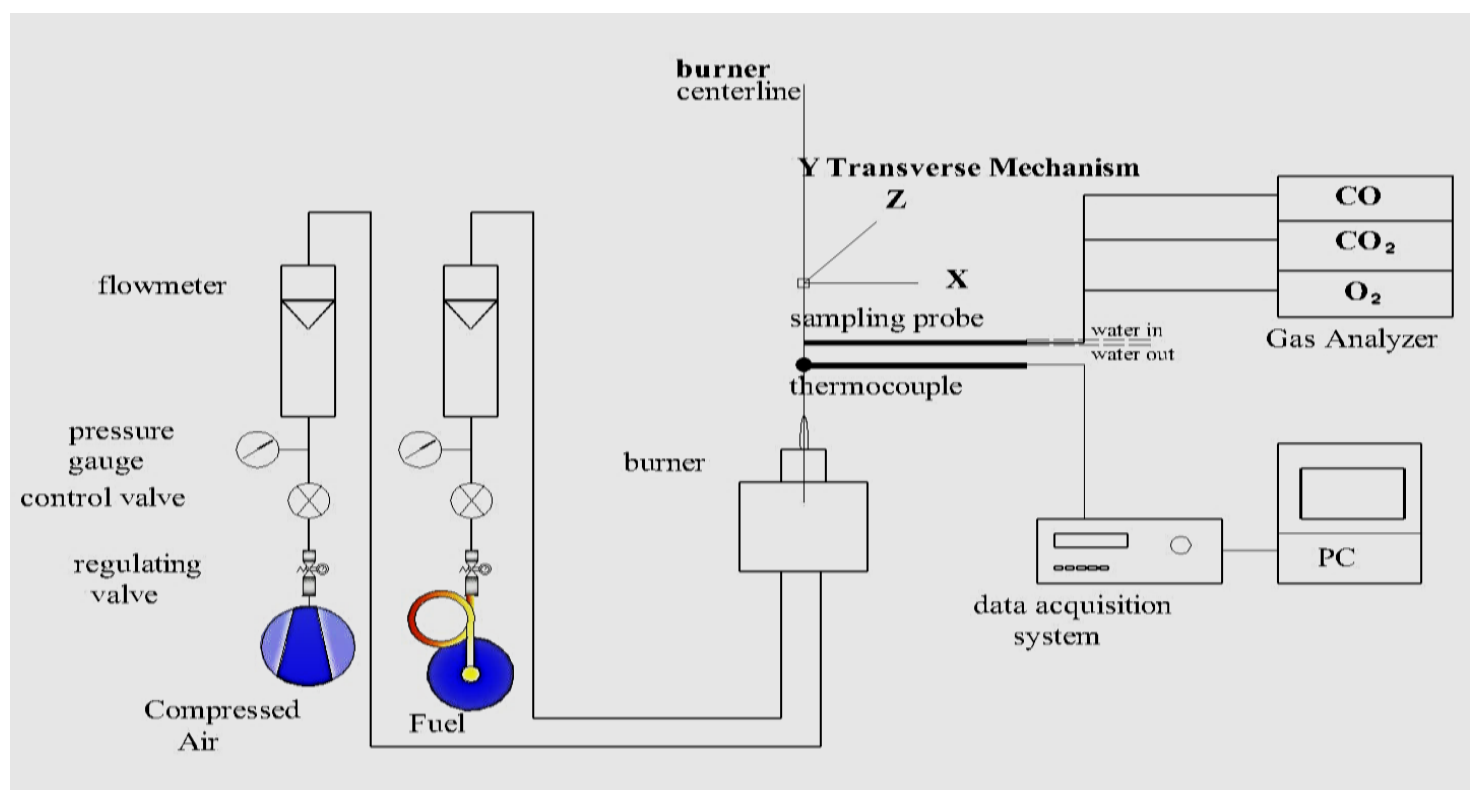

Fig. 2 Schematic diagram for temperature and emission measurements.

The gas analysis was carried out at the burner center line at different locations along the flame axis. The gas sampling probe is water cooled stainless steel probe of inner diameter equal to $1 \mathrm{~mm}$.

The gas analysis was measured using infrared multi-gas analyzer unit, model MGA3000. The $\mathrm{CO}_{2}$ and $\mathrm{CO}$ is a single beam infrared technology. The $\mathrm{O}_{2}$ measurement technique is paramagnetic cell.

Tests for flame appearance and flame length were carried out for two condition, the first at constant Reynolds number for air at $\operatorname{Re}=2500$ and different equivalence ratios $\varnothing=(1,1.6,2.2,2.6,3)$, the second at constant $\emptyset=1.6$ and different $\operatorname{Re}=(2000,2500,3000,3500)$.

Tests for centerline flame temperature and emission $\left(\mathrm{Co}, \mathrm{Co}_{2}\right.$ and $\left.\mathrm{O}_{2}\right)$ are carried out for two conditions, the first at constant Reynolds number for air at $\mathrm{Re}=2500$ and two equivalence ratios $\varnothing=(1$ and 2.6), the second at constant $\varnothing=1.6$ and two $\mathrm{Re}=(2000$ and 3000).

Table 1: illustrates the details of flow conditions for varies tests. 
Table 1 Operating conditions.

\begin{tabular}{|c|c|c|c|c|c|c|}
\hline $\begin{array}{c}\text { Air jet } \\
\text { velocity } \\
(\mathrm{m} / \mathrm{s})\end{array}$ & $\begin{array}{c}\text { Fuel jet } \\
\text { velocity } \\
(\mathrm{m} / \mathrm{s})\end{array}$ & $\begin{array}{c}\text { Air flow } \\
\text { rate } \\
\left(\times 10^{-4}\right. \\
\left.\mathrm{m}^{3} / \mathrm{s}\right)\end{array}$ & $\begin{array}{l}\text { Total fuel } \\
\text { flow rate }(\times \\
\left.10^{-5} \mathrm{~m}^{3} / \mathrm{s}\right)\end{array}$ & $\operatorname{Re}$ & $\Phi$ & $\begin{array}{c}\text { Air } \\
\text { velocity/ } \\
\text { fuel } \\
\text { velocity }\end{array}$ \\
\hline \multicolumn{7}{|c|}{ Conditions at fixed air flow rate } \\
\hline 1.70 & 0.028 & 6.75 & 2.30 & 2500 & 1 & 59.86 \\
\hline 1.70 & 0.045 & 6.75 & 3.68 & 2500 & 1.6 & 37.41 \\
\hline 1.70 & 0.062 & 6.75 & 5.06 & 2500 & 2.2 & 27.21 \\
\hline 1.70 & 0.074 & 6.75 & 5.98 & 2500 & 2.6 & 23.02 \\
\hline 1.70 & 0.085 & 6.75 & 6.91 & 2500 & 3 & 19.95 \\
\hline \multicolumn{7}{|c|}{ Conditions at fixed equivalence ratio } \\
\hline 1.36 & 0.036 & 5.40 & 2.95 & 2000 & 1.6 & 37.41 \\
\hline 1.70 & 0.045 & 6.75 & 3.68 & 2500 & 1.6 & 37.41 \\
\hline 2.04 & 0.054 & 8.10 & 4.42 & 3000 & 1.6 & 37.41 \\
\hline 2.38 & 0.064 & 9.45 & 5.16 & 3500 & 1.6 & 37.41 \\
\hline
\end{tabular}

\section{RESULTS AND DISCUSSIONS}

\section{Flame Appearance and Flame-Length}

In the present study a comparison has been carried out between two types of IDF with different configuration designs (CoA and Slot)

The three variables taken into consideration in the present study which are considered to be affecting the flame shape and structure are as follows:

1- Burner configuration

2- Air flow rate

3- Fuel flow rate

The second and third factors are depending on each other i.e. at constant air velocity with the increase of fuel velocity it the same as constant fuel velocity and decrease the air velocity.

The study investigates two conditions, the first one is variable air velocity with constant fuel velocity, and the second is constant air to fuel velocity but with different quantities i.e. constant equivalence ratio $(\varnothing)$. The two investigations are applied to both the CoA and slot burners.

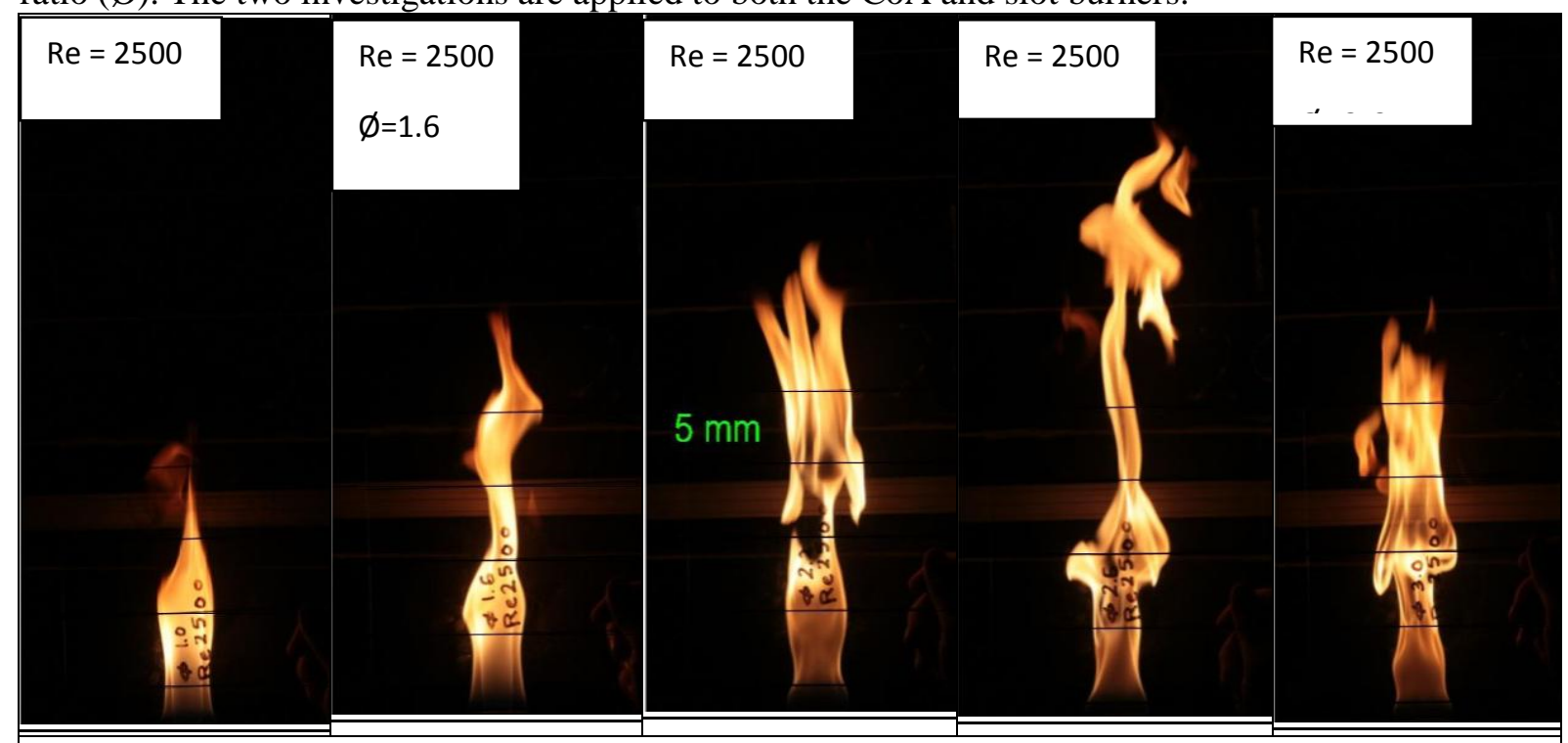

Fig. 3a Flame photos for CoA burner at constant Re. 

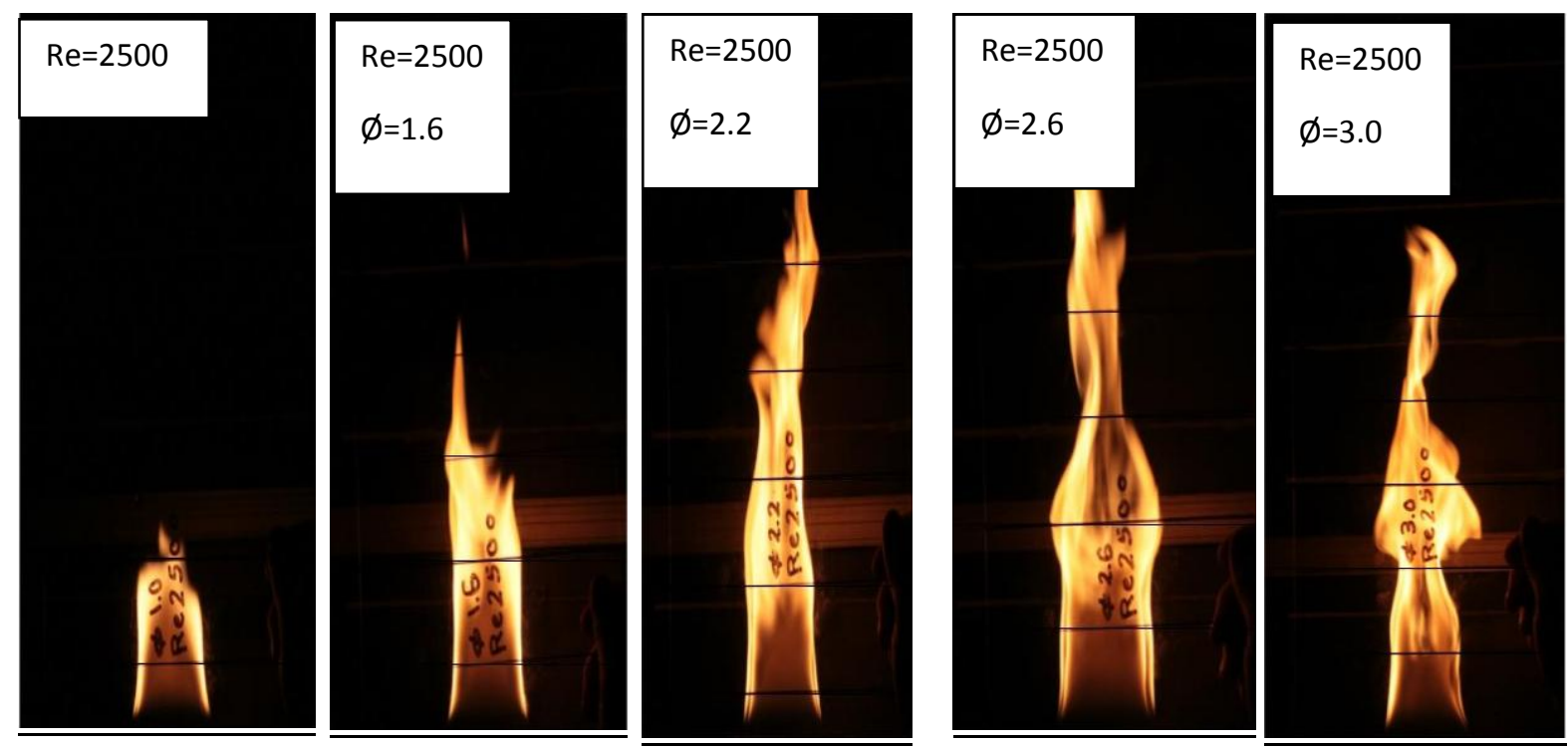

Fig. 3b Flame photos for slot burner at constant Re.
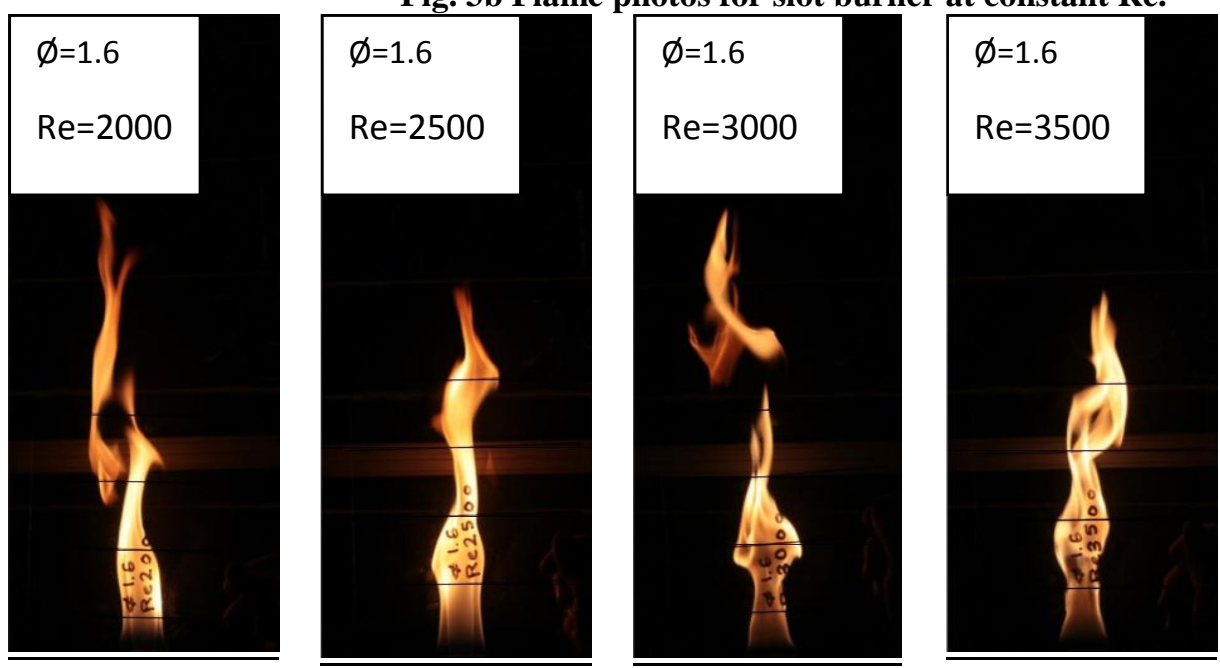

Fig. 3c Flame photos for CoA burner at constant $\emptyset$.
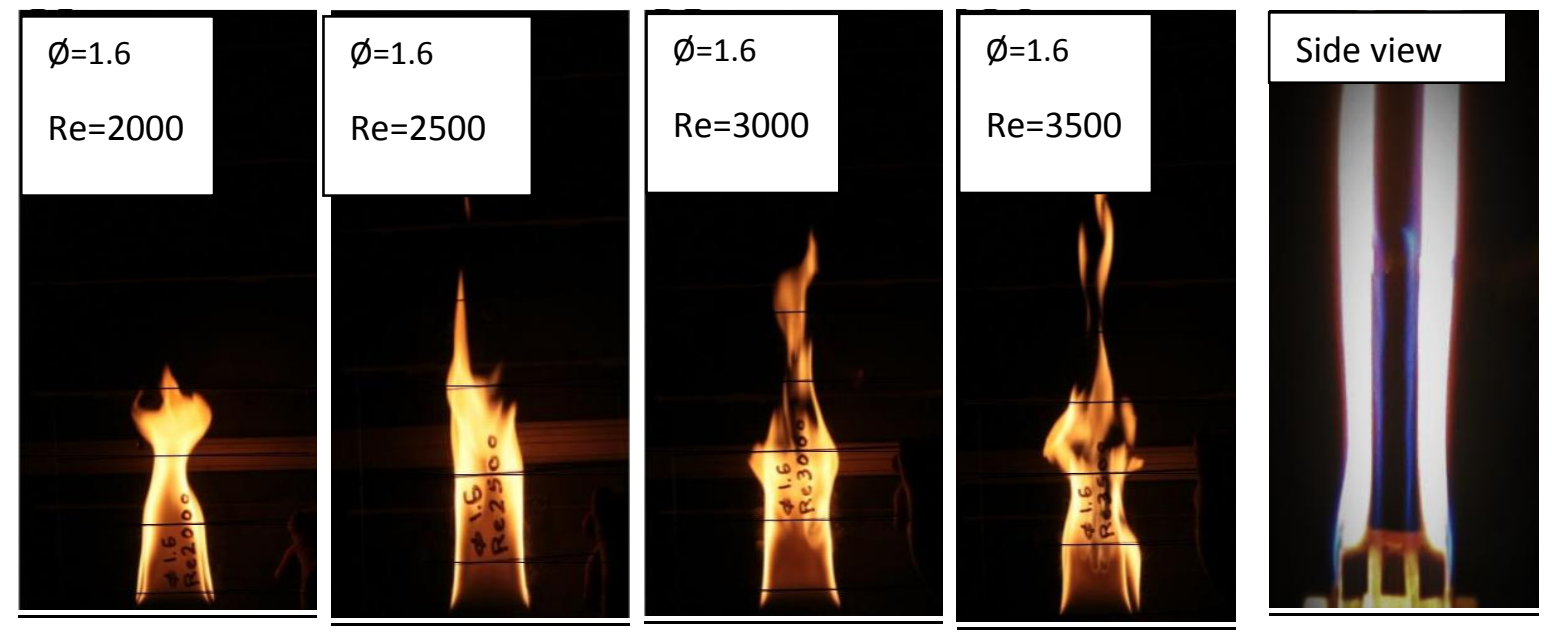

Fig. 3d Flame photos for slot burner at constant $\emptyset$. 


\section{a- Effect of changing $\emptyset$ with fixed Re.}

It is found that the flame consists of two main parts flame base and flame torch as shown in fig (3a).

The flame base or entrainment zone is close to burner port, this part contains the entrainment process. The high air velocity with respect to fuel velocity make the fuel entrained into the air and mixing between air and fuel is rapid enough to form a premixed zone with a blue flame color.

This entrainment zone is affected by $\varnothing$, as $\varnothing$ increased with fixed Re decreasing the difference between air velocity and fuel velocity and hence decrease entrainment effect.

The second part is the flame torch, it is above flame base, this part has a yellow shape which means that part is burning in diffusion mode and is like a vertical cylinder with orange wings at the torch end which is indication of soot formation, However these wings are decreased with increasing velocity ratio, at very high air velocity this zone convert from yellow to blue color indicating that burning is changes from fuel rich to fuel lean, In this case the difference between flame base and torch is a flame neck.

It is observed that at high enough velocity ratio the flame is like a hollow cylinder with the same structure base and torch and when the ratio decreased this hollow disappeared to be inner cone base flame with closed end and flame torch with closed end.

This part called mixing and combustion zone in literatures [9, 10, 11, and 17].

b- Effect of changing Re with fixed $\emptyset$.

When $\varnothing$ kept at constant value and Re is changed, by changing air velocity the fuel velocity also changed by the ratio of air velocity to give constant $\varnothing$ i.e. in this condition the ratio of air velocity to fuel velocity are constant but with difference values of velocities.

The flame shape and construction is the same as the previous condition (base and torch) as shown in fig (3c). However, at low velocity values for air and fuel the flame is hollow at the center and at relatively high values the flame end is converged to the center and has a closed end.

\section{2- SLOT BURNER}

a- Effect of changing $\emptyset$ with fixed Re.

Slot burner also consists of two main parts; flame base and flame torch, However, it is not the same as CoA burner. It consists of five layers; the first is at the burner center and it has a mixture of air and fuel (or invisible flame), at both sides of this layer two identical layers (called entrainment layers) are found, and at the sides of entrainment layers two identical layers (called mixing and combustion layers) are also, as shown in fig. (3b, 3d).

This layers are consisted according to the configuration of the slot burner where the contact between air and fuel is two lines so that an entrainment area is found in this shape.

The main parts are entrainment, mixing and combustion. The entrainment zone is like a prism in shape, it is due to differences between air and fuel velocities, which makes the fuel entrained into the air. Due to difference between air velocity and fuel velocity mixing air and fuel more rapidly, gives a premixed zone with blue color.

This entrainment zone is effected by $\varnothing$, as $\varnothing$ increased with fixed Re the velocity ratio between air and fuel is decreased i.e. decreasing difference between air velocity and fuel velocity decrease entrained effect.

The second part is mixing and combustion zone. This part has a yellow color and prism shape which means that part of the flame is burning in diffusion mode, also there is very little orange wings at the end which is an indication of soot formation. This wings are decreased with increasing velocity ratio. At very high air velocity this zone converts from yellow to blue color indicating that burning has been changed from fuel rich to fuel lean.

The observation showed that, at high enough velocity ratio the flame is a hollow at the burner center with the same structure (it is seems as separate flames) and when the ratio decreased this hollow disappeared, where the two entrainment layers and mixing and combustion layers are converged to each other make a closed end.

\section{b- Effect of changing Re with fixed $\emptyset$.}


As $\varnothing$ kept at constant and variable Re i.e. change air velocity the fuel velocity also changed by the ratio of air velocity to give constant $\varnothing$.

The flame shape and construction is the same as the previous condition (entrainment and mixing and combustion zones) as shown in fig (3d). However, at low velocity values for air and fuel the flame is hollow at the center, and at relatively high values the flame end is converged into the center and has a closed end.

From previous discussion it is found that both burner have two zone (entrainment and mixing and combustion), but the difference is due to (slot burner configuration), the entrainment zone is larger than that of $\mathrm{CoA}$ burner, and the mixing and

combustion zones are smaller as shown in fig. (4),
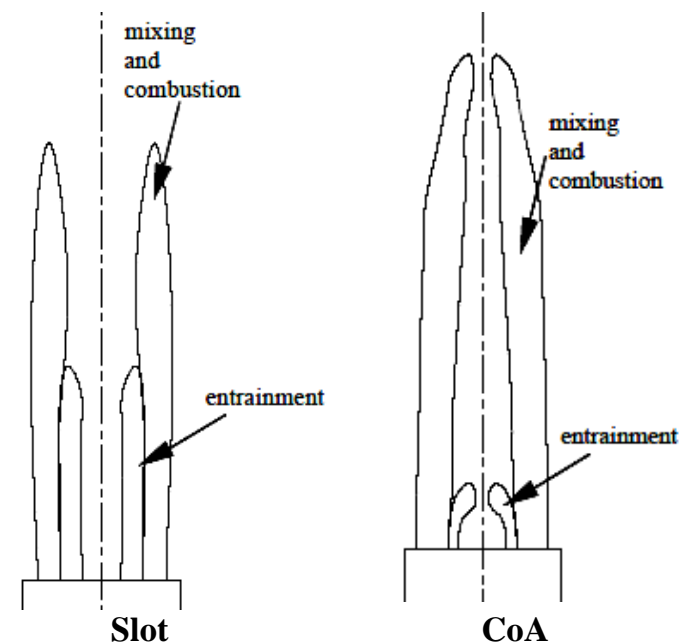

Fig. (4) Flame zones. entrainment zone characterized by a blue color as premixed zone, and the orange wings not found in slot burner.

\section{FLAME LENGTH}

The flame length is sensitive to fuel flow rate, where at constant Re (constant air flow rate) and changing fuel flow rate by changing $\varnothing$ from 1 to 3 it is seen that the flame length increases, as shown in fig (5). The flame length is an indication for the residence time, so that for slot burner the residence time is smaller than that for CoA burner because the flame length for CoA burner is larger than slot burner.

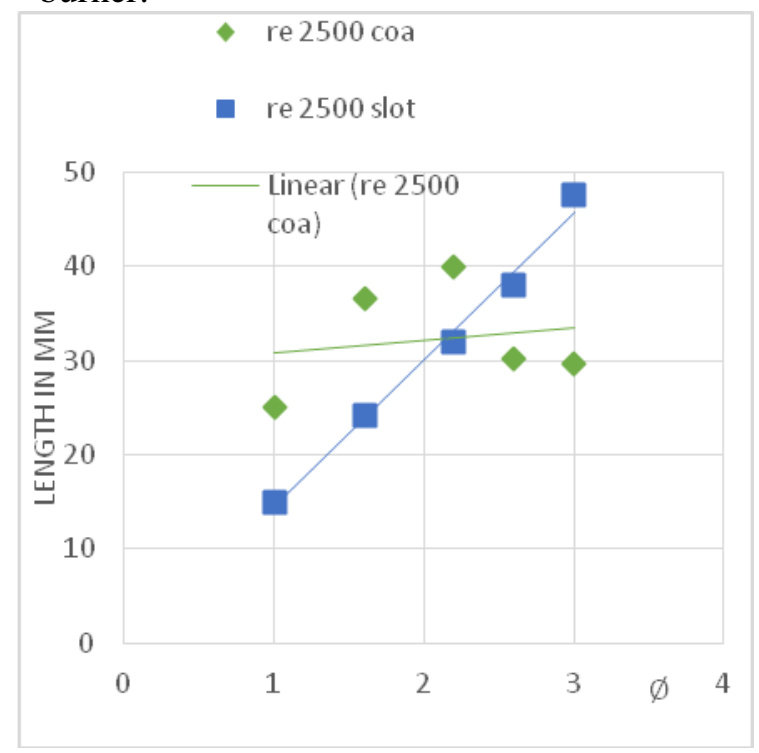

Constant Reynolds

\section{CENTERLINE TEMPERATURE}

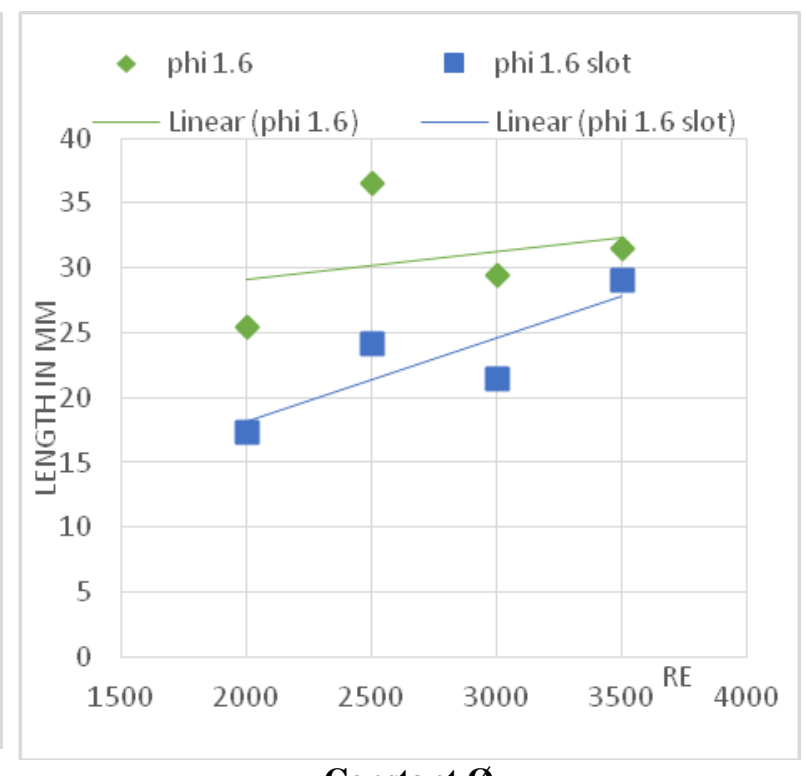

Constant $\varnothing$

The burner centers is the center of tube for CoA burner and the center of intermediate slot for slot burner. The temperatures for slot burner is higher than that CoA burner for the same conditions in all cases as shown in fig, $(7 \mathrm{a}, 7 \mathrm{~b})$, this can be attributed to the following:

Due the difference between the two burner configurations, the contact area between air and fuel for slot burner is approximately double the contact area for CoA burner, which makes entrainment zone for slot burner is larger.

The distance between the center of air exit and the contact line between air and fuel for CoA burner is approximately two and half times that for slot burner, as illustrated in fig. (1).

From the previous discussion it is clear that the entrainment effect for slot burner is higher. 
For the case of CoA burner:

At constant $\varnothing=1.6$ as shown in fig. (6), at $\mathrm{Re}=2000$ the flame is hollow from the center and at the center this is as air stream (invisible flame), so that the temperature is very low and approximately constant, When increases to $\mathrm{Re}=3000$ the two zones are intended to converge to burner center so that the temperature increased.

The curves gives in fig. (7), Indicate that at constant $\operatorname{Re}=2500$, at $\varnothing=1$ the flame is hollow from the center and the temperature is very low, When increasing the $\varnothing$ to 2.6 the temperature increases.

For the case of Slot burner:

At constant $\varnothing=1.6$ as shown in fig. (6). at $\operatorname{Re}=2000$ the flame seems to be separate flames so that at the center there is an air stream (invisible flame) but the temperature is more high than that for CoA burner, which is due to reasons discussed before, also that the entrainment zone are in contact at a point approximately at $135 \mathrm{~mm}$ because the temperature at this point is the maximum temperature, When Re increases to 3000 the flame zones are converged to each other so that temperatures are increased and it is observed that the maximum temperature is plateau which indicate that the entrainment zones are converged at the center.

The curves gives in fig. (7), Indicate that at constant $\operatorname{Re}=2500$, at $\varnothing=1$ the flame seems to be separate flames, the entrainment zone is in contact in a point at the center, When $\varnothing$ increases to 3 zones are converged to the center, and the entrainment zone are contact at the center in line so that maximum Temperature is a plateau.

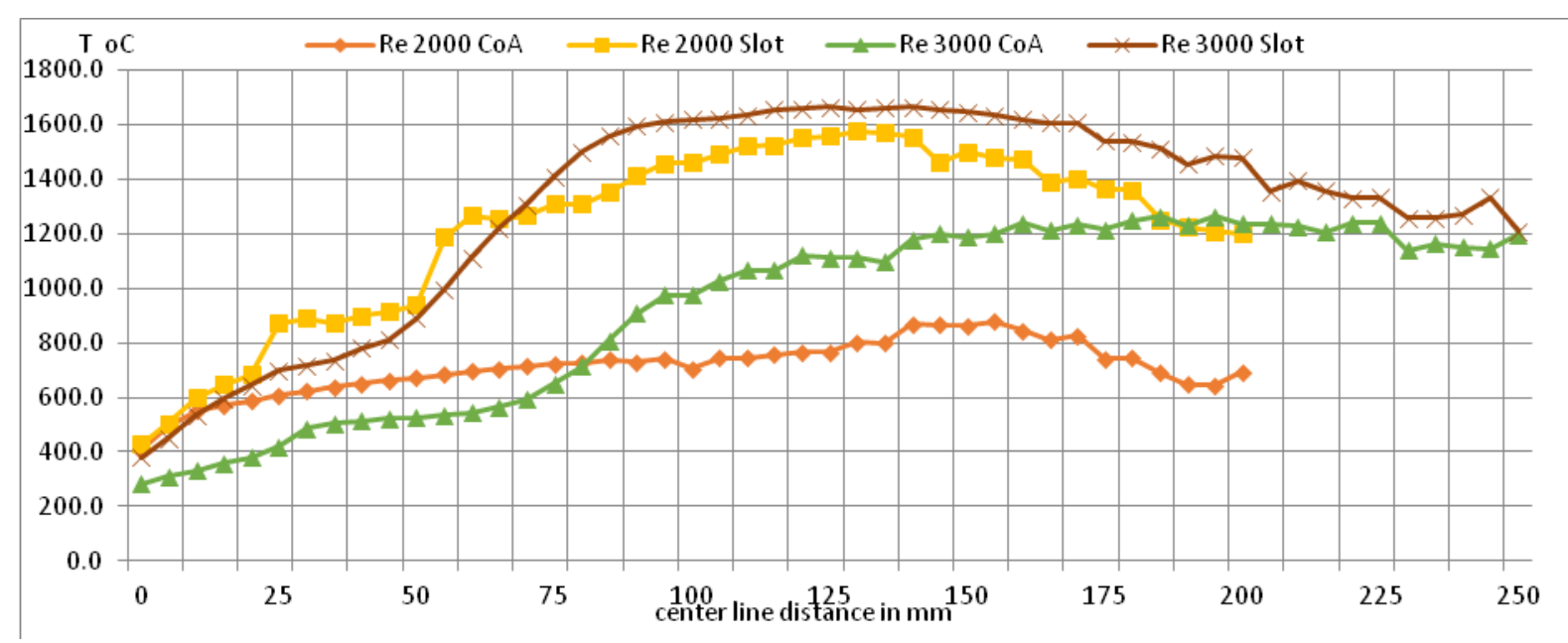

Fig. (6) Centerline temperature at constant $\emptyset$.

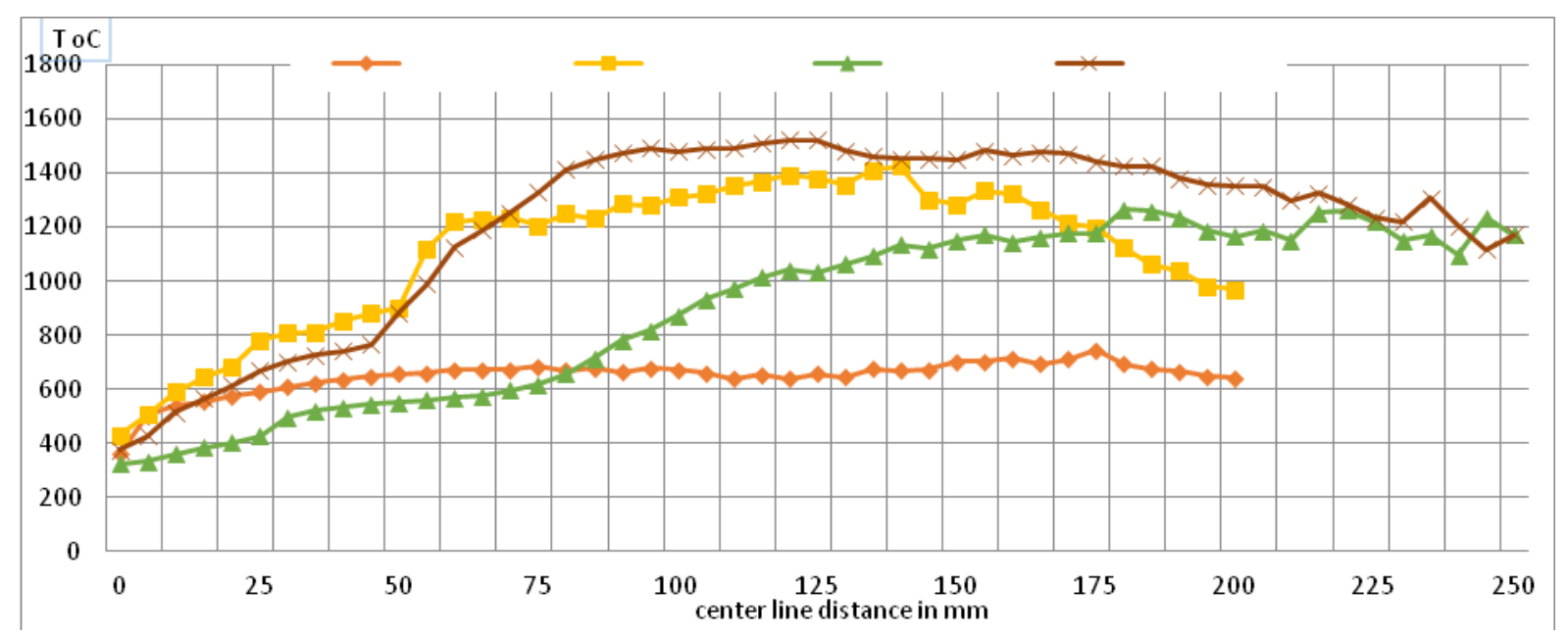

Fig. (7) Centerline temperature at constant Re. 


\section{CENTERLINE EMISSIONS}

Oxygen centerline concentrations are shown in fig. $(8,9)$, Oxygen concentration is an indication for the degree of combustion, and its trend is opposite to the temperature trend, As $\mathrm{O}_{2}$ concentration for $\mathrm{CoA}$ burner is higher than that for slot burner, its indicates that CoA flame center line have a very lean mixture because it has high oxygen concentration, which indicates that the entrainment effect is low, and mixing is bad. For slot burner the concentration is low, indicates that good mixing between air and fuel is achieved.

It is clear that Oxygen trend is increased in post flame zone due to entrained of the ambient air. Consumption for slot burner is rapid than CoA burner.

$\mathrm{CO}_{2}$ centerline concentrations are shown in fig. $(8,9)$, Carbon in fuel is oxidized to $\mathrm{CO}_{2}$ and $\mathrm{Co}, \mathrm{CO}_{2}$ indicates complete combustion, his trend is similar to temperature trend and is opposite to $\mathrm{O} 2$ trend, therefore, $\mathrm{CO}_{2}$ for slot burner is higher than that for $\mathrm{CoA}$ burner, the peak value for slot burner is at distance from the burner outlet smaller than that for CoA burner which indicates that the mixing in slot burner is better than that for CoA burner.

Co centerline concentrations as shown in fig. $(8,9)$, Co is an indication of premixed combustion mode, Therefore, it takes the same trend for temperature and it support the present investigation, for slot burner at high Re or at high $\emptyset$ the Co has a plateau trend at the peak value, which indicates that the region is a premixed zone which in the present study called entrainment zone, and has a very low values at low Re or at low $\varnothing$.

At low Re or at low $\varnothing$ for CoA burner the flame is hollow as indicated before so that the concentration of $\mathrm{O} 2$ is high and $\mathrm{Co} 2$ and $\mathrm{Co}$ are low.
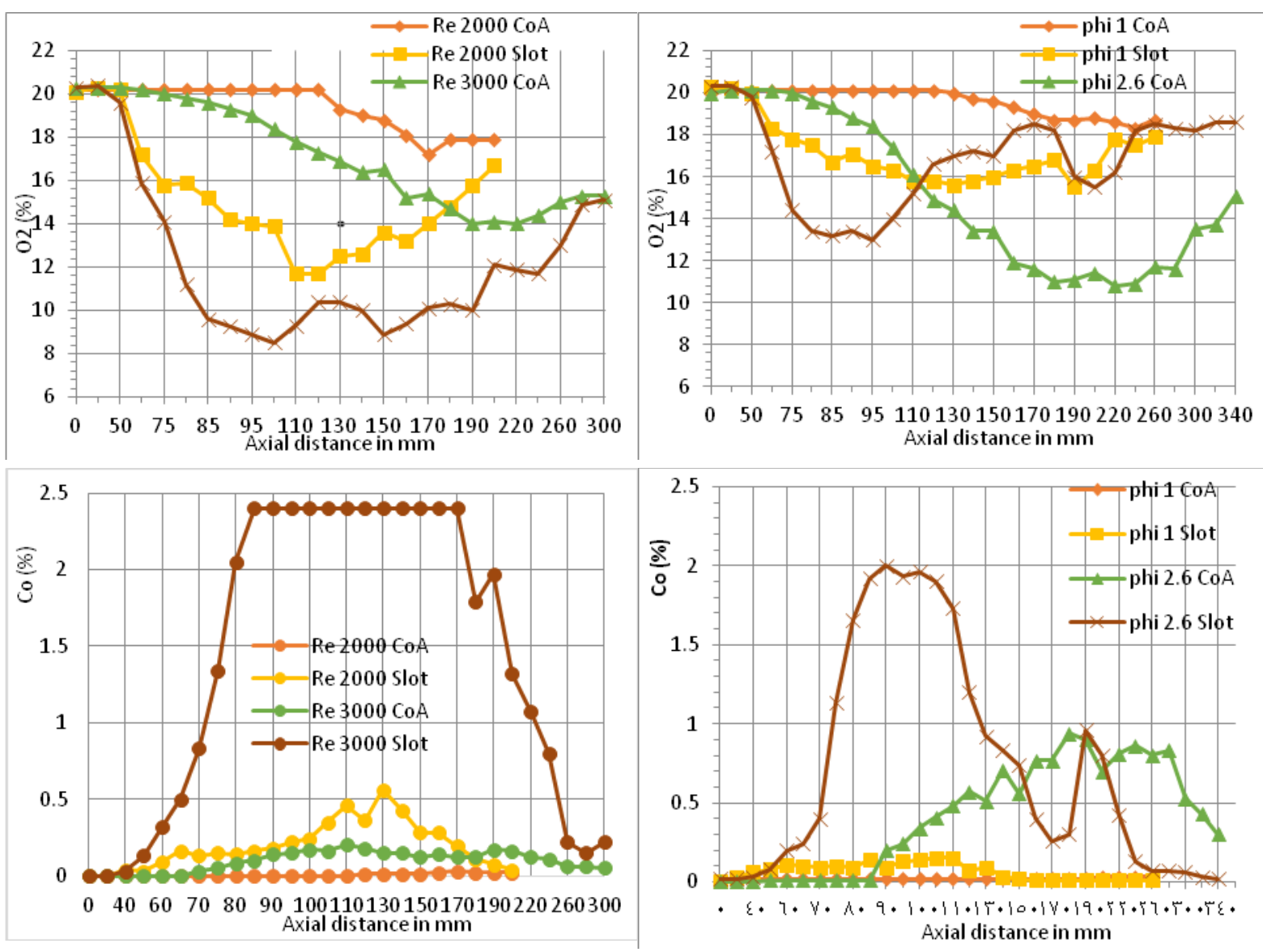


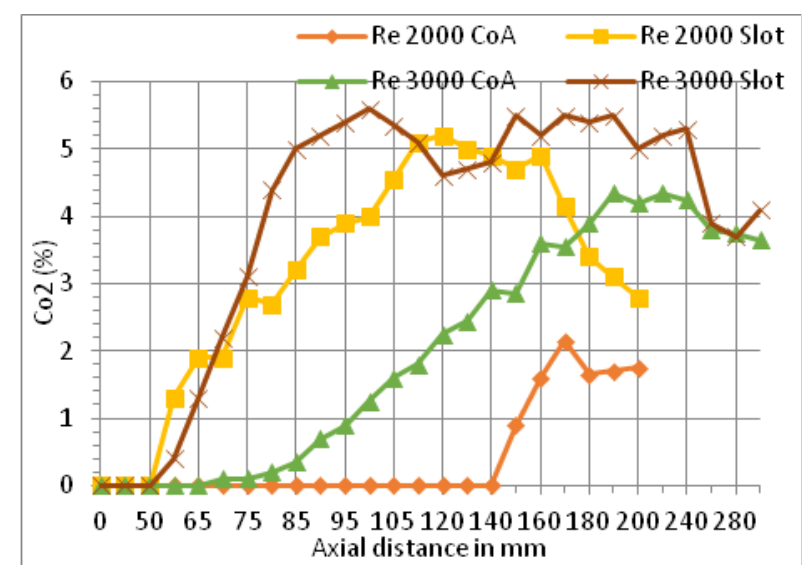

Fig. (8) Centerline emissions at constant $\varnothing$.

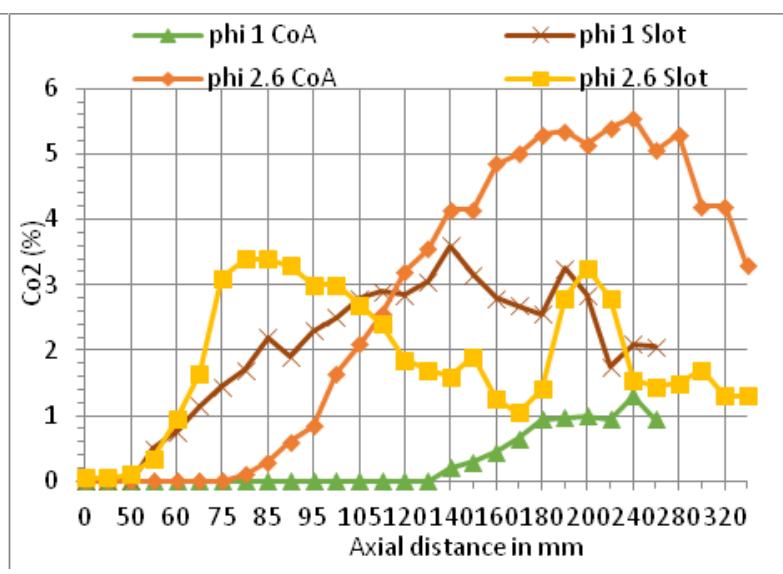

Fig. (9) Centerline emissions at constant Re.

\section{CONCLUSIONS}

- The slot burner configuration makes the entrainment zone is larger than that for CoA burner, which means that more of fuel is burning in premixed mode.

- The centerline temperature for slot burner is high than that for CoA burner.

- $\mathrm{O}_{2}$ centerline concentration for slot burner is lower than that for CoA burner, and consumed rapidly, this indicates a good mixing.

- $\mathrm{CO}_{2}$ centerline concentration for slot burner is higher than that for CoA burner, this indicates a complete combustion.

- Co centerline concentration for slot burner is higher than that for CoA burner, this indicates burning is in premixed mode at the area of high Co.

\section{ACKNOWLEDGMENT}

Thanks for Al-Azhar University, Faculty of Engineering, Mechanical engineering Department, and the combustion \& Internal combustion Engines laboratory which facilitates all the requirement to carry out the study.

\section{REFERENCES}

[1] Baukal CE, Gebhart B. A review of empirical flame impingement heat transfer correlations. International Journal of Heat and Fluid Flow 1996; 17:386.

[2] Kilham JK, Purvis MRI. Heat transfer from normally impinging flames. Combustion Science and Technology 1978; 18:81.

[3] Fairweather M, Kilham JK, Mohebi-Ashtiani A. Stagnation point heat transfer from turbulent methaneeair flames. Combustion Science and Technology; 1984:225.

[4] Purvis MRI. Heat transfer from normally impinging hydrocarbon oxygen flames. $\mathrm{PhD}$ thesis, University of Leeds; 1974.

[5] Sonju OK, Hustad J. Experimental study of turbulent jet Diffusion flames. AIAAProgress in Astronautics and Aeronautics 1984; 95:320.

[6] Rigby JR, Webb BW. An experimental investigation of Diffusion flame jet impingement heat transfer. In: Proceedings of the ASME/JSME Thermal Engineering Joint Conference $1985 ; 3: 117$.

[7] A. Sinha, R. Ganguly, I.K. Puri, Control of confined nonpremixed flames using a microjet, International Journal of Heat and Fluid Flow 26 (2005) 431-439.

[8] W.P. Partridge, N.M. Laurendeau, Nitric oxide formation by inverse Diffusion flames in staged-air burners, Fuel 74 (10) (1995) 1424-1430.

[9] A. Sobiesiak, J.C. Wenzell, Characteristics and structure of inverse flames of natural gas, Proceedings of the Combustion Institute 30 (2005) 743-749.

[10] L.K. Sze, C.S. Cheung, C.W. Leung, Appearance, temperature and Noxemission of two inverse Diffusion flames with different port design, Combustion and Flame 144 (2006) 237245. 
[11]Wu KT, Essenhigh RH. Mapping and structure of inverse Diffusion flames of methane. In: Proceedings of the 20th international symposium on combustion. The Combustion Institute; 1984. p. 1925-32.

[12] TOSHIMI TAKAGI, ZHE XU, and MASAHARU KOMIYAMA, Preferential Diffusion Effects on the Temperature in Usual and Inverse Diffusion flames, combustion and flame106:252-260 (1996).

[13] C.R. Shaddix, T.C. Williams, L.G. Blevins and R.W. Schefer, Flame structure of steady and pulsed sooting inverse jet Diffusion flames, Proc. Combust. Inst. 30 (2005), pp. 15011508.

[14] Kaplan CR, Kailasanath K. Flow-field effects on soot formation in normal and inverse methane-air Diffusion flames. Combust Flame 2001; 124:275-94.

[15] S.Brohe, C. Delvosalle, G. Marlairl, A two-thermocouple probe for radiation corrections of measured temperatures in compartment fires, fire safety journal 39 (2004), pp. 399-411.

[16] k. Hashiba, M. Hasatani, S. Sugiyama, A correctional calculation method for thermocouple measurements of temperatures in flames, combustion and flame 24 (1975), pp. $35-41$.

[17] Linda G. Blevins, Nancy Y.C. Yang, George W. Mulholland, Ronald W. Davis, Eric B. Steel, Early Soot From Inverse Diffusion flames, Fuel Chemistry Division Preprints 2002, 47(2), pp. 740. 